
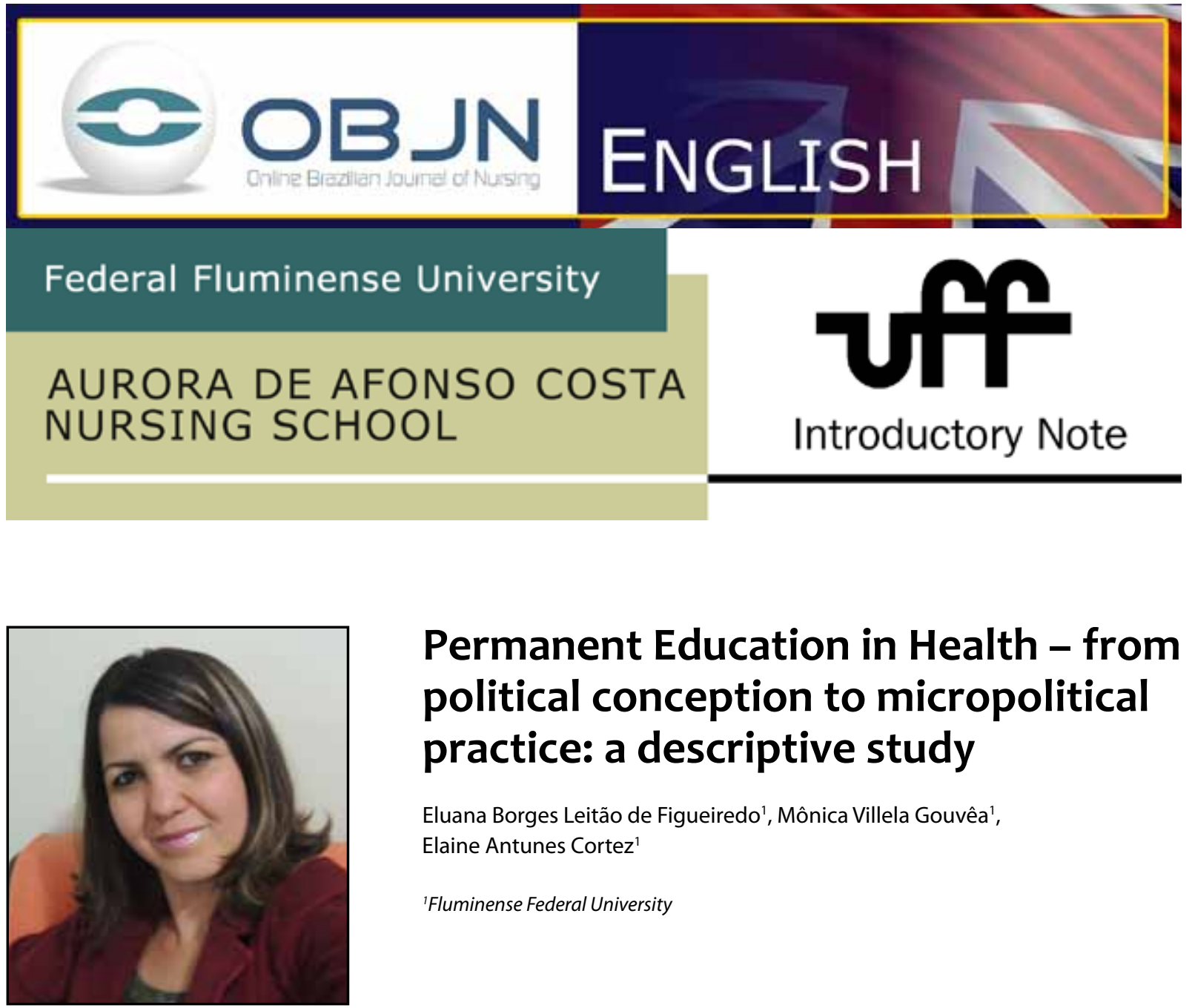

\title{
Permanent Education in Health - from political conception to micropolitical practice: a descriptive study
}

\author{
Eluana Borges Leitão de Figueiredo', Mônica Villela Gouvêa', \\ Elaine Antunes Cortez ${ }^{1}$ \\ 'Fluminense Federal University
}

\begin{abstract}
Aim: To analyze the strategies of permanent education in health (EPS, in Portuguese) taking into account the Brazilian National Policy of Permanent Education in Health (PNEPS, in Portuguese) and micropolitical construction; to understand the situation of EPS management and other health practices, to identify the predominant educational concept and its directions; to describe the strengths and the limitations associated with incorporating the EPS actions in the work routines in healthcare; to correlate the concept of EPS in PNEPS in terms of practical organization.

Method: This is a descriptive and exploratory study using a qualitative approach, to be performed through the analysis of EPS processes within the municipal spectrum. The data will be collected through an analysis of official documents and semi-structured interviews with managers/other professionals responsible for the processes of education in the region, and with professionals who have already participated in the activities of the Family Health Strategy. The probable period for collecting the data will be from October 2013 to December 2013.

Descriptors: Health Public Policy; Continuing Education; Unified Health System; Health Education.
\end{abstract}




\section{PROBLEM SITUATION AND ITS SIGNIFICANCE}

Considering that the Brazilian Unified Health System (SUS, in Portuguese) and the development seen in SUS's principles and directives can be interpreted as an unfinished masterpiece, the program of permanent education in health (EPS, in Portuguese) is a strategy that congregates all problems of practice as the object of reflection in terms of teams ${ }^{(1)}$, as it is important to consolidate SUS and to improve the quality of healthcare ${ }^{(2)}$.

In this context, the Brazilian National Policy in Permanent Education in Health (PNEPS, in Portuguese) was designed to assist and stimulate reflection with regard to the daily practice of healthcare services, amplifying the autonomy of the subjects involved, and promoting the construction of transformational and propositional practices. Besides the fact that educational institutions and health services work together, there are still some gaps in professional education, sometimes separating theory from practice ${ }^{(3)}$.

This study aims to consider EPS within the context of PNEPS and the micropolitical construction of the municipal health services.

The motivation started with the professional career of the researcher who worked in a basic care unit in 2011, and today works in an emergency care unit of the city under consideration. The work processes performed in both units demonstrated the distance between theory and practice, and the gaps in professional education when it comes to confronting the complex demands presented. It was also seen that, regarding the professionals, they received instructions providing them with techniques to perform their roles, without including in this process any reflection about the reality of the professional environment. Such experience brought up the fact that, besides the educational institutions, the public health services have a fundamental role to play in qualifying health professionals, making them able to reflect on, and capable of intervening in, their daily work routine.

When dealing with the topic of EPS, we believe that this study will contribute to field research in the areas of education and health, and the entrepreneurship of the many actors that constitute the scenarios, which permit the permanent reflection of multi-professional teams about their practices.

\section{GUIDING QUESTIONS}

What are the actions and the predominant pedagogical concept in the process of EPS that are being used in the municipality? Are these actions in accordance with the PNEPS? Do the workers understand the place of work as a learning and transforming space?

\section{AIM}

To analyze the strategies of EPS considering PNEPS and its micropolitical construction; to understand the context of EPS management and the practices of health, identifying the predominant educational concept and its directives; to describe the strength and the limitations when it comes to incorporating the actions of EPS in the daily lives of those who work in healthcare; to correlate the concept of EPS in PNEPS in a practical organization.

\section{ASSUMPTION}

This study is based on the assumption that EPS is a facilitating pedagogical strategy aimed at transforming the actions of the local realities 
of health services, as well as the role of the health worker. Considering this assumption, this study can represent an effective possibility to generate an understanding of EPS to health professionals, besides activating the process of permanent reflection with regard to health practices.

\section{METHOD}

This is a descriptive and exploratory research, which adopts a qualitative approach. It is based on the scenario created in a municipality located in the Medium Paraíba do Sul River Valley, in the state of Rio de Janeiro, Brazil. The data will be collected using two research techniques: a) documentary analysis and b) semi-structured interviews. The period of data collection may start in October 2013 and end in December 2013.

The analysis of documents will be based on the evidencing records of educational activities performed in the last two years on the part of the basic care professionals of the municipality under consideration.

The semi-structured interviews will be undertaken with approximately 30 people who are considered key-informants in the region/ municipality. They will be divided in two groups: a) management professionals involved with educational processes, and b) Family Health Strategy (ESF, in Portuguese) professionals who have already participated in education activities developed in the municipality.

The data analysis will be done using Bardin's content analysis approach.

\section{REFERENCES}

1. Dicionário da Educação Profissional em Saúde [homepage in the internet]. Educação permanente em saúde [cited 2013 Apr 5]. Available from: http://www.epsjv.fiocruz.br/dicionario/verbetes/ edupersau.html

2. Capra MLP. A educação permanente em saúde como dispositivo de gestão setorial e de produção de trabalho vivo em saúde. Porto Alegre. Tese [Doutorado em Saúde Pública] - Universidade Federal do Rio Grande do Sul; 2011.

3. Schmidt SMS, Backes VMS, Cartana MHF, Budó MLD, Noal HC, Silva RM. Facilities and difficulties in planning training-service integration: a case study. Online braz j nurs [Internet]. 2011 Oct [Cited 2013 Aug 28]; 10 (2): [about 7 p.]. Available from: http://www.objnursing.uff.br/index. php/nursing/article/view/3243. http://dx.doi. org/10.5935/1676-4285.20113243

\section{Project Data}

Project of dissertation of the Professional Master Program in Education of Health, from the Fluminense Federal University. The project is under appreciation by the Ethics in Research Committee, according to CAAE 18747913.9.0000.5243.

Tutor: Mônica Villela Gouvêa

Co-tutor: Elaine Antunes Cortez

Received: $26 / 08 / 2013$

Revised: 28/08/2013

Approved: 30/08/2013 